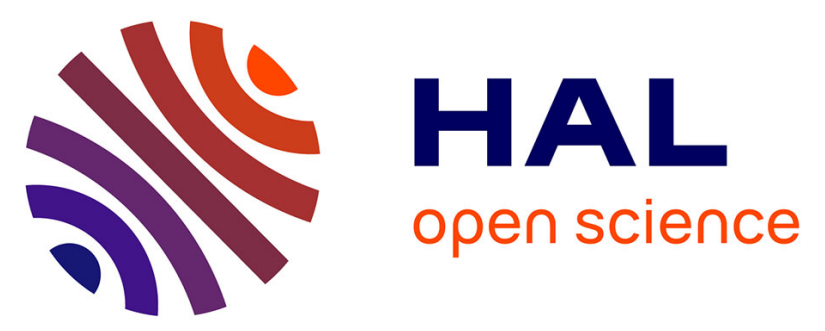

\title{
Thermally induced inter-ring haptotropic rearrangements in $\pi$-complexes of molybdenum with nitrogen containing polyaromatic heterocycles: A DFT study
}

E.O. Fetisov, I.P. Gloriozov, M.S. Nechaev, S. Kahlal, J.-Y. Saillard, Y.F. Oprunenko

\section{To cite this version:}

E.O. Fetisov, I.P. Gloriozov, M.S. Nechaev, S. Kahlal, J.-Y. Saillard, et al.. Thermally induced inter-ring haptotropic rearrangements in $\pi$-complexes of molybdenum with nitrogen containing polyaromatic heterocycles: A DFT study. Journal of Organometallic Chemistry, 2017, 830, pp.212-218. 10.1016/j.jorganchem.2016.12.004 . hal-01515134

HAL Id: hal-01515134

https://hal-univ-rennes1.archives-ouvertes.fr/hal-01515134

Submitted on 22 May 2017

HAL is a multi-disciplinary open access archive for the deposit and dissemination of scientific research documents, whether they are published or not. The documents may come from teaching and research institutions in France or abroad, or from public or private research centers.
L'archive ouverte pluridisciplinaire HAL, est destinée au dépôt et à la diffusion de documents scientifiques de niveau recherche, publiés ou non, émanant des établissements d'enseignement et de recherche français ou étrangers, des laboratoires publics ou privés. 
The nitrogen atom in quinoline helps stabilizing the transition state in the inter-ring haptotropic rearrangement process.

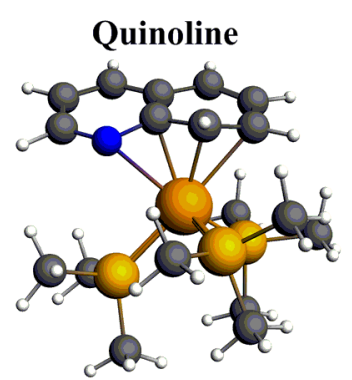

II-TS4

$\Delta \mathrm{G}^{*}=25.1 \mathrm{kcal} / \mathrm{mol}$ vs. naphtalene

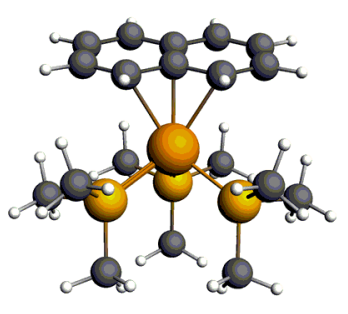

V-TS

$\Delta \mathrm{G}^{*}=31.6 \mathrm{kcal} / \mathrm{mol}$ 


\title{
Thermally Induced Inter-Ring Haptotropic Rearrangements in $\pi$ - Complexes of Molybdenum with Nitrogen Containing Polyaromatic Heterocycles: a DFT Study
}

\author{
Evgenii O. Fetisov, ${ }^{\mathrm{a} \dagger}$ Igor P. Gloriozov, ${ }^{\mathrm{a}}$ Mikhail S. Nechaev, ${ }^{\mathrm{a}, \mathrm{b}, \mathrm{c}}$ Samia Kahlal, ${ }^{\mathrm{d}}$ Jean-Yves \\ Saillard ${ }^{\mathrm{d} *}$ and Yuri F. Oprunenko, ${ }^{\mathrm{a} *}$ \\ ${ }^{a}$ Department of Chemistry, M.V. Lomonosov Moscow State University, Vorob'evy Gory, Moscow 119899, \\ Russia. E-mail: oprunenko@org.chem.msu.ru. \\ ${ }^{b}$ A. V. Topchiev Institute of Petrochemical Synthesis, Russian Academy of Sciences, Leninsky Prospect 29, \\ Moscow 119991, Russia. \\ ${ }^{\mathrm{c}}$ N.D. Zelinsky Institute of Organic Chemistry, Russian Academy of Sciences, Leninsky Prospect 47, Moscow \\ 119991, Russia. \\ ${ }^{\mathrm{d}}$ Institut des Sciences Chimiques de Rennes, UMR 6226 CNRS-Université de Rennes 1, 35042 Rennes cedex, \\ France. E-mail : saillard@ univ-rennes1.fr. \\ ${ }^{\dagger}$ Present address: Department of Chemistry and Chemical Theory Center, University of Minnesota, 207 Pleasant \\ Street SE, Minneapolis, Minnesota 55455, USA.
}

Electronic supplementation information (ESI) available: Cartesian coordinates of all the computed stationary points in the .mol format.

\begin{abstract}
Inter-ring haptotropic rearrangements (IRHRs) are well-known phenomena in fluxional ogranometallic chemistry. They are mainly observed for transition metal complexes with polyaromatic ligands (PALs), but are usually limited to PALs without heteroatoms. Here, we report DFT studies of recent experimentally observed IRHRs in heterocyclic complexes of Mo. Four different ligands (quinoline, isoquinoline, quinoxaline, and indolyl) have been investigated. Overall, structural and energetic trends agree well with available experimental data. In addition, mechanistic trends and heteroatom participation are discussed and elucidated to further understanding of IRHRs in heterocyclic polyaromatic complexes in particular, and haptotropic processes in general.
\end{abstract}




\section{INTRODUCTION}

Transition metal complexes play a decisive role in the transformation of simple organic substances and generation of important innovative derivatives such as technological precursors, materials for science and industry, new polymers and medicines [1]. This is related to their structural peculiarities and flexibility, and, in the case of complexes of polyaromatic ligands (PALs) for instance, it is mainly due to their propensity to undergo different intramolecular inter-ring rearrangements [2]. Recently, the ability of such complexes to catalyze many organic reactions was fully recognized [3]. Their catalytic action is often explained by the generation of intermediates and/or transition states with reduced hapticity, in the course of such rearrangements or reactions with substrates. Additional coordination capabilities promote binding of the substrate and reagents to the metal and their further transformations within the coordination sphere of the metal. Moreover, transition metal PAL complexes are widely used for the activation of different positions in the aromatic ligands and their further derivatization by reactions with electrophiles [4] and nucleophiles [5]. All of this has led to significant prospects of transition metal PAL complexes in the fields of material chemistry [6] and pharmacology [7]. In medicine, such complexes are used as drugs, in particular, against malaria [8] and as anti-HIV and antineoplastic agents [9], as well as contrast agents in MRI [10]. Recently, it was also shown that some of these compounds are very valuable as precursors for constructing new electronic [11], optical [12], sensor and switch [13] devices.

A lot of information and data is devoted to complexes of transition metal with monoaromatic ligands [14] but considerably less to complexes of PALs [4], especially, to compounds with extra-large ligands, which are sometime elusive or at least problematic to characterize, such as corannulene [15], coronene [16], fullerenes [17], nanotubes [18], graphites [19], and graphenes [19].

PAL complexes are interesting per se, due to their diverse dynamic behavior [20]. For the past three decades, intramolecular reversible and irreversible inter-ring haptotropic rearrangements (IRHRs) in these complexes were intensively studied. Such processes consist of the shifting, from one ring to another one, of the $\mathrm{ML}_{\mathrm{n}}$ organometallic groups along the plane of the carbo- [21] or heterocyclic [22] PALs. A few examples of $\eta^{6} \rightleftarrows \eta^{6}-\pi, \pi$-IRHRs for readily available, stable and exhaustively investigated $\mathrm{Cr}(\mathrm{CO})_{3}$ complexes are presented in Scheme 1. 

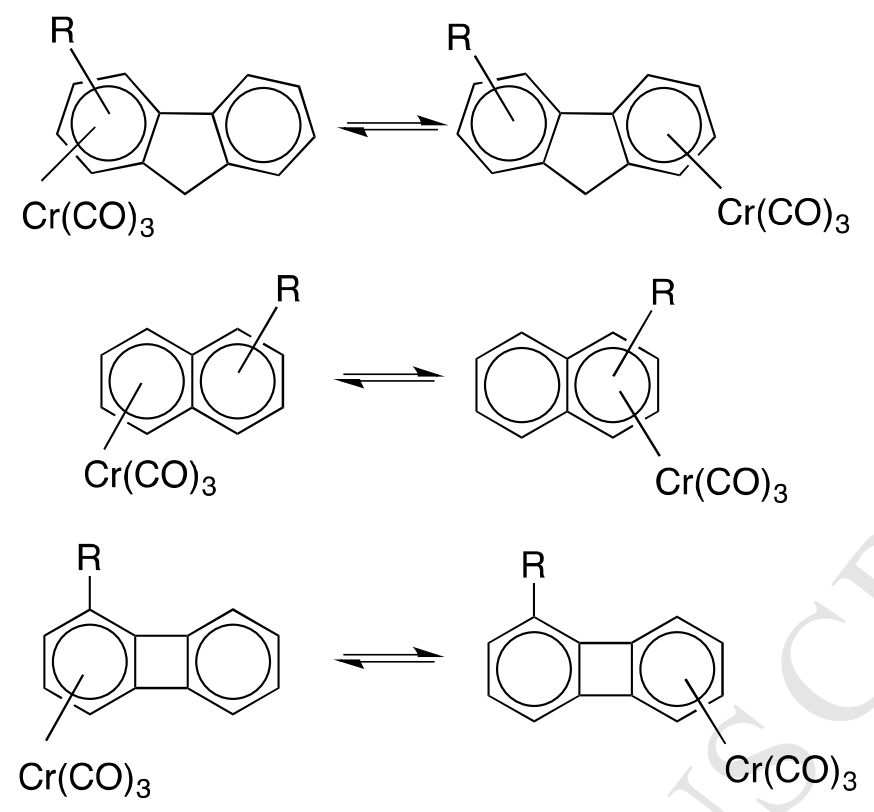

$\mathrm{R}=\mathrm{H}, \mathrm{D}, \mathrm{CH}_{3}$

Scheme 1. Examples of some inter-ring haptotropic rearrangements

It should be noted that usually IRHRs occur in complexes of PALs which do not contain heteroatoms (such as naphthalene [23] or biphenylene [24]), and only little is known about $\eta^{6}$ $\equiv \eta^{6}$-IRHR in fluorene-like compounds containing ligands with at least one heteroatom in the five-membered ring (such as dibenzothiophene [22] or carbazole derivatives [25]). According to density functional theory (DFT) calculations [21], these rearrangements proceed via the ligand periphery and direct heteroatom participation was not found.

This situation changed with the pioneering papers of Parkin and co-workers [26,27] on Mo complexes of PALs containing nitrogen atom(s): indolyl, quinoline, isoquinoline and quinoxaline. First of all, an unusual Mo $\eta^{5}$-complex of indolyl, I-a, was synthesized, where the organometallic group (OMG) unexpectedly binds to the nitrogen-containing ring. This complex was obtained from the corresponding $\eta^{1}$-complex I-c under the conditions of phosphine shortage. In very mild conditions, $\mathbf{I}-\mathbf{a}\left(80^{\circ} \mathrm{C}\right.$, benzene) rearranges irreversibly to Ib via a thermally induced $\eta^{5} \rightarrow \eta^{6}$-IRHR. It is noteworthy that the reverse process could be induced photochemically and probably proceeds reversibly [26] (Scheme 2). 
<smiles>CC(C)C</smiles>

I-c

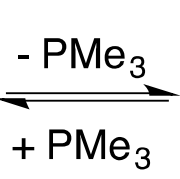

$+\mathrm{PMe}_{3}$

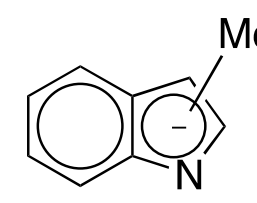

I-a
$\mathrm{MoH}\left(\mathrm{PMe}_{3}\right)_{3}$

$80^{\circ} \mathrm{C}$

$h v$<smiles></smiles>

I-b

Scheme 2. IRHR in Mo complex of indolyl

Then, $\eta^{6} \rightleftharpoons \eta^{6}$-IRHR was investigated for the first time in complexes of Mo with heterocyclic analogs of naphthalene, namely, quinoline, isoquinoline and quinoxaline [27]. All the studied rearrangements are depicted in Scheme 3. For example, the reaction of quinoline with $\mathrm{Mo}\left(\mathrm{PMe}_{3}\right)_{6}\left(80^{\circ} \mathrm{C}\right.$, benzene) leads to an $\eta^{6}$-complex with metal localization on the heterocyclic ring (II-a), which is thermally unstable. A metal shift occurs between the heteroand carbo-cyclic rings with the formation of the $\eta^{6}$-complex II-b. Reaction of isoquinoline with $\mathrm{Mo}\left(\mathrm{PMe}_{3}\right)_{6}$ at room temperature leads to the formation of a kinetic $\eta^{2}$-product (Scheme 3). At $100^{\circ} \mathrm{C}$ in benzene, this $\eta^{2}$-product irreversibly rearranges to the $\eta^{6}$-complex III-a with the coordination of the OMG on the heterocyclic ring. But, similarly as for quinoline, such coordination is thermodynamically unfavorable and, in the course of further temperature increase up to $150^{\circ} \mathrm{C}$, III-a irreversibly rearranges to the carbocyclic complex III-b. The reverse $\eta^{6}=\eta^{6}$-IRHR when the OMG migrates from the carbocyclic to the heterocyclic ring $($ III-b $\rightarrow$ III-a) proceeds photochemically and irreversibly at room temperature. As well as in the case of the two other ligands, the quinaxoline complex IV-a was found thermodynamically unstable, and it irreversibly rearranges at $130^{\circ} \mathrm{C}$ to the isomer having the localization of the OMG on the carbocyclic ring. The reverse $\eta^{6} \rightleftarrows \eta^{6}$-IRHR when the OMG migrates from the carbocyclic to the heterocyclic ring proceeds photochemically and irreversibly at room temperature. 


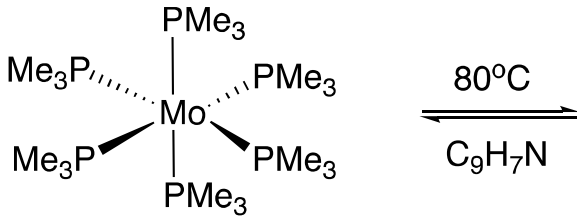

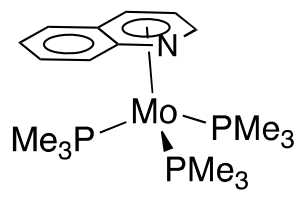

II-a

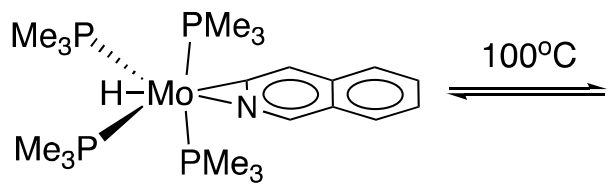

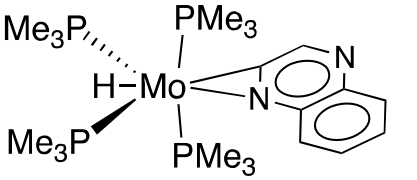<smiles>[18OH]</smiles>

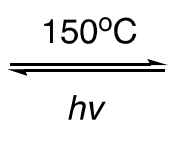

III-a

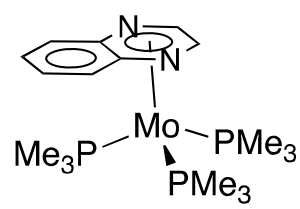

IV-a

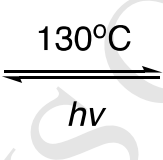

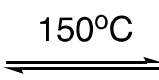

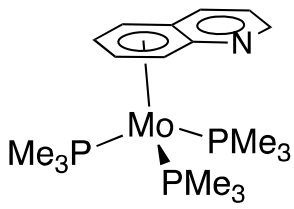

II-b

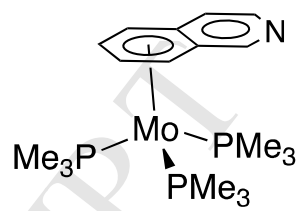

III-b

IV-b

Scheme 3. IRHRs in Mo complexes of quinoline, isoquinoline and quinoxaline

All the previously mentioned IRHRs in these new complexes were investigated only experimentally, and theoretical analysis of their underlying mechanisms has not yet been done. In this paper, we report the first theoretical study of these mechanisms, performed by means of DFT calculations.

\section{COMPUTATIONAL DETAILS}

All the geometry optimizations, characterizations of stationary points and calculations of reaction energy profiles have been performed on an MVS-100K supercomputer at the Joint Supercomputer Center (JSCC) (Moscow), at the DFT level with the PRIRODA-04 program written by Laikov [28]. We used the PBE functional [29], the TZV2P three-exponential basis set of Gauss-type functions for valence electrons [28] (basis set specification: $\{3,1\} /\{5,1\}$ for $\mathrm{H},\{3,3,2\} /\{5,5,2\}$ for $\mathrm{C}, \mathrm{N}$, and $\mathrm{P}$ and $\{5,5,4\} /\{9,9,8\}$ for Mo), and the TZV2p (SBK-JC) relativistic pseudopotential [30] for core electrons of all the atoms of the molecular systems for which calculations were performed. We have shown previously the validity of this approach for evaluating geometries, mechanisms and thermodynamic parameters of organometallic reactions [4,20-24]. Moreover, it has been checked that the available X-ray structures of the complexes investigated in this work are correctly reproduced by the calculations, in terms of both conformations and bond distances and angles (see Section S1 in 
the SI). For example, the average deviation of the computed distances with respect to the experimental ones is only $0.05 \AA$. All the stationary points were identified by analyzing Hessians. Hapticities of the stationary and transition states were deduced from bond distances and bond orders [31] (see Section S2 in the SI). The thermodynamic functions (Gibbs activation energies, $\Delta G$ ) were calculated using statistical rigid rotator-harmonic oscillator equations. The correlation of the observed transition states with the corresponding potential energy surface minima was checked by constructing internal reaction coordinates (IRC). The reaction energy profiles plotted in Figures 1,2, 5-7, correspond to the computed IRC curves (total energy $\Delta \mathrm{E} v s$. reaction coordinates).

In order to get a more detailed picture of the bonding within the computed stationary points, fragment interaction analyses have been performed on these structures, at the GENCI French national computer centers, with the help of the ADF2013 program [32], the fragments being the PAL on one side and the $\mathrm{ML}_{\mathrm{n}}$ unit on the other side. Indeed, the ADF code enables analyzing the Kohn-Sham molecular orbitals on the basis of the fragment orbitals, allowing identification of those responsible for bonding and electron transfer. The ADF calculations were carried out as single-points on the PRIRODA-optimized structures with the PBE functional and an STO all-electron TZ2P basis set [33].

\section{RESULTS AND DISCUSSION}

Naphthalene complex. In order to elucidate the role played by the heteroatom(s) in the above described IRHR processes, we have first performed calculations on the naphthalene analog of complexes II-IV, $\left(\eta^{6}-\mathrm{C}_{10} \mathrm{H}_{8}\right) \mathrm{Mo}\left(\mathrm{PMe}_{3}\right)_{3}(\mathbf{V})$ as a fully carbocyclic mechanistical reference [35]. Experimentally, the degenerate $\eta^{6} \rightarrow \eta^{6}$-IRHR rearrangement of $\mathbf{V}$ can be observed only with the use of labeled ligands, but no such experiments have been performed so far. The full reaction path $\mathbf{V} \rightarrow \mathbf{V}$-TS $\rightarrow \mathbf{V}$-IM $\rightarrow \mathbf{V}$-TS $\rightarrow \mathbf{V}$ is presented in Figure 1 . The IRHR is found to proceed through two symmetric (mirror images) transition states and one intermediate, the three of them being very close in energy (within $0.2 \mathrm{kcal} / \mathrm{mol}$ ), as well as in geometry (peripheral $\eta^{3}-\mathrm{C}_{10} \mathrm{H}_{8}$ coordination, see Figure 1). The activation barrier for this process is $\Delta G_{150^{\circ} \mathrm{C}}=31.6 \mathrm{kcal} / \mathrm{mol}$. Similar results have been obtained for related naphthalene complexes $[4 b, 34]$. 


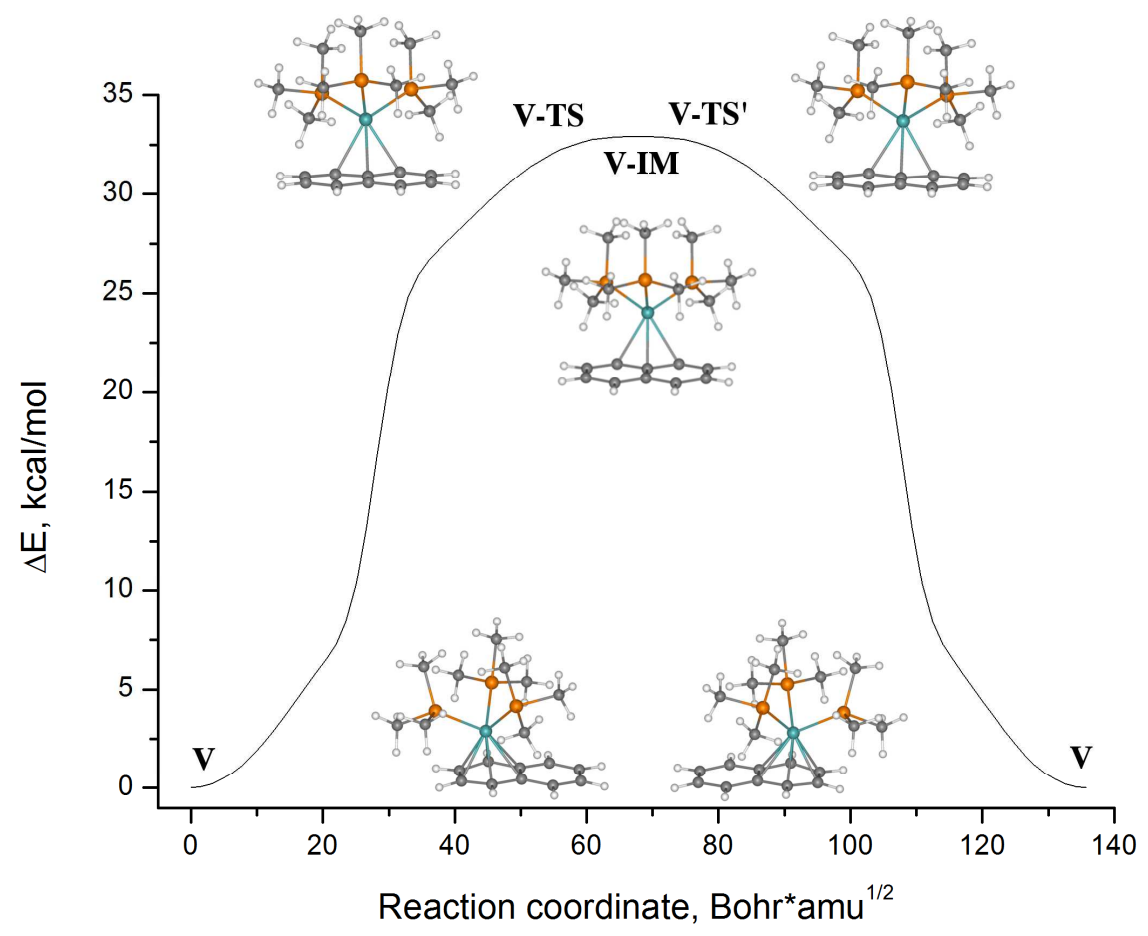

Figure 1. IRC energy profile for the degenerate IRHR $\mathbf{V} \rightleftarrows \mathbf{V}$. Note that V-TS, V-IM and VTS' are almost isoenergetic.

The fragment interaction analysis of V-IM (see Computational Details) indicates a donation of $0.26 \mathrm{e}$ from the occupied $\pi$ orbitals of naphthalene into the three accepting orbitals of the $\mathrm{Mo}\left(\mathrm{PMe}_{3}\right)_{3}$ tripod. On the other hand, the vacant $\pi^{*}$ orbitals of naphthalene receive $0.76 \mathrm{e}$ from the occupied $\mathrm{t}_{2 \mathrm{~g}}$-type of $\mathrm{Mo}\left(\mathrm{PMe}_{3}\right)_{3}$. For comparison, the electron transfer counterparts in the $\eta^{6}$-coordinated global minimum $\mathbf{V}$ are $0.65 \mathrm{e}$ and $1.05 \mathrm{e}$. These values illustrate the importance of metal $\pi$-type backdonation in such species.

Quinoline complex. We now discuss the IRHR in the quinoline species II, which is the most interesting from the point of view of heteroatom participation. Calculated relative Gibbs free energies indicate significantly larger thermodynamic stability of II-b relative to II-a $\left(\Delta \Delta G_{150^{\circ} \mathrm{C}}=-5.30 \mathrm{kcal} / \mathrm{mol}\right)$ and thus practically irreversibility of $\eta^{6} \rightarrow \eta^{6}$-IRHR II-a $\rightarrow$ II-b, which agrees with the experimental results. This II-a $\rightarrow$ II-b process can theoretically proceed via two alternative mechanisms. Both computed mechanisms are presented in Figure 2. In the first case, the metal shift proceeds along the carbocyclic edge via the $\eta^{3}$-transition states $\eta^{3}$-II-TS1 and $\eta^{3}$-II-TS2 and the intermediate $\eta^{3}$-II-IM1 according to the scheme II-a $\rightarrow$ II-TS1 $\rightarrow$ II-IM1 $\rightarrow$ II-TS2 $\rightarrow$ II-b (maximum on the potential energy surface (PES) 
$\left.\Delta G_{150^{\circ} \mathrm{C}}=26.7 \mathrm{kcal} / \mathrm{mol}\right)$. Unsurprisingly, this pathway is very similar to that obtained for the naphthalene complex $\mathbf{V}$. In the second case, the metal shift proceeds along the heterocyclic edge of the ligand according to the scheme II-a $\rightarrow$ II-TS3 $\rightarrow$ II-IM2 $\rightarrow$ II-TS4 $\rightarrow$ II-b (maximum on the PES $\Delta G_{150^{\circ} \mathrm{C}}=25.1 \mathrm{kcal} / \mathrm{mol}$ ). In this pathway, the trajectory of the metal tripod is fairly different from that observed in V. In II-TS3 and II-IM2, the Mo atom is mainly bonded to nitrogen and its $\mathrm{C}(\mathrm{H})$ neighbor $(\mathrm{Mo}-\mathrm{N}=2.17 \AA$ and $2.03 \AA$, Mo- $\mathrm{C}=2.20 \AA$ and $2.51 \AA$, respectively). Two and one weak Mo-C additional contacts are also present in IITS3 and II-IM2, respectively (see Figure 2). In II-TS4 Mo is coordinated to both rings in a $\eta^{4}$ fashion (Figure 2), with two internal shorter Mo-C bonds $(2.28 \AA$ and $2.23 \AA$ ) and two longer external bonds (Mo-N = $2.53 \AA$ and Mo-C $=2.60 \AA$ ). Thus, metal-nitrogen bonding character is maintained along a large part of the IRHR. This fact is associated with an activation barrier that is $1.6 \mathrm{kcal} / \mathrm{mol}$ lower, as compared to the other pathway. The formation of II-IM2, in which Mo is mainly coordinated to the external $\mathrm{C}=\mathrm{N}$ bond, is favored by the lower aromatic nature of the heterocycle. There is also a substantial participation of the $\mathrm{N}$ lone pair to the bonding to Mo in II-IM2 (donation of $0.13 \mathrm{e}$, as compared to the $\pi$-donation of $0.21 \mathrm{e}$ and the $\pi^{*}$-backdonation of $\left.0.78 \mathrm{e}\right)$. In fact the bonding in II-TS4 retains several features of that in II-IM2 (see below).

The lower aromatic nature of quinoline as compared to naphthalene allows an easier out-ofplane distortion which in turn allows the fairly unsymmetrical $\eta^{4}$-coordination mode adopted in II-TS4. The fragment interaction analysis indicates a donation of $0.43 \mathrm{e}$ from the occupied orbitals of quinoline into the metal accepting orbitals, of which $0.08 \mathrm{e}$ can be considered as providing from the $\mathrm{N}$ lone pair. This is illustrated in the MO diagram of Figure 3, in which are sketched the stabilizing interactions between the HOMO (major involved $\pi$-type occupied orbital) and the lone-pair MO of quinoline, and the set of the three hybrid-type accepting orbitals of the $\mathrm{Mo}\left(\mathrm{PMe}_{3}\right)$ moiety. [37] The major occupied MO of II-IM2 which is associated with the Mo-N bonding through the participation of the $\mathrm{N}$ lone pair is plotted in Figure 4, side by side with its homolog in II-TS4. Thus, the ligand-to-metal electron donation is larger in IITS4 than in V-IM or V-TS. A similar situation arises for the metal-to-ligand backdonation which is of $0.90 \mathrm{e}$ in II-TS4, due to the lowest energy of the three vacant $\pi^{*}$ orbitals of the Ncontaining quinoline ligand which can substantially interact with the three occupied " $\mathrm{t}_{2 \mathrm{~g}}$ "type, as sketched in Figure 3. [37] Thus, the movement along the heteroatom-containing side is facilitated as compared to moving along the other side. Such possibility was discussed by Czerwinski et al. [35] because of a higher rate found for the IRHR in $\eta^{6}$-chromium 
tricarbonyl complexes of ortho-aminobiphenyl in comparison with the corresponding paraisomer (Scheme 4). Later, this assumption was confirmed by theoretical calculations [36].

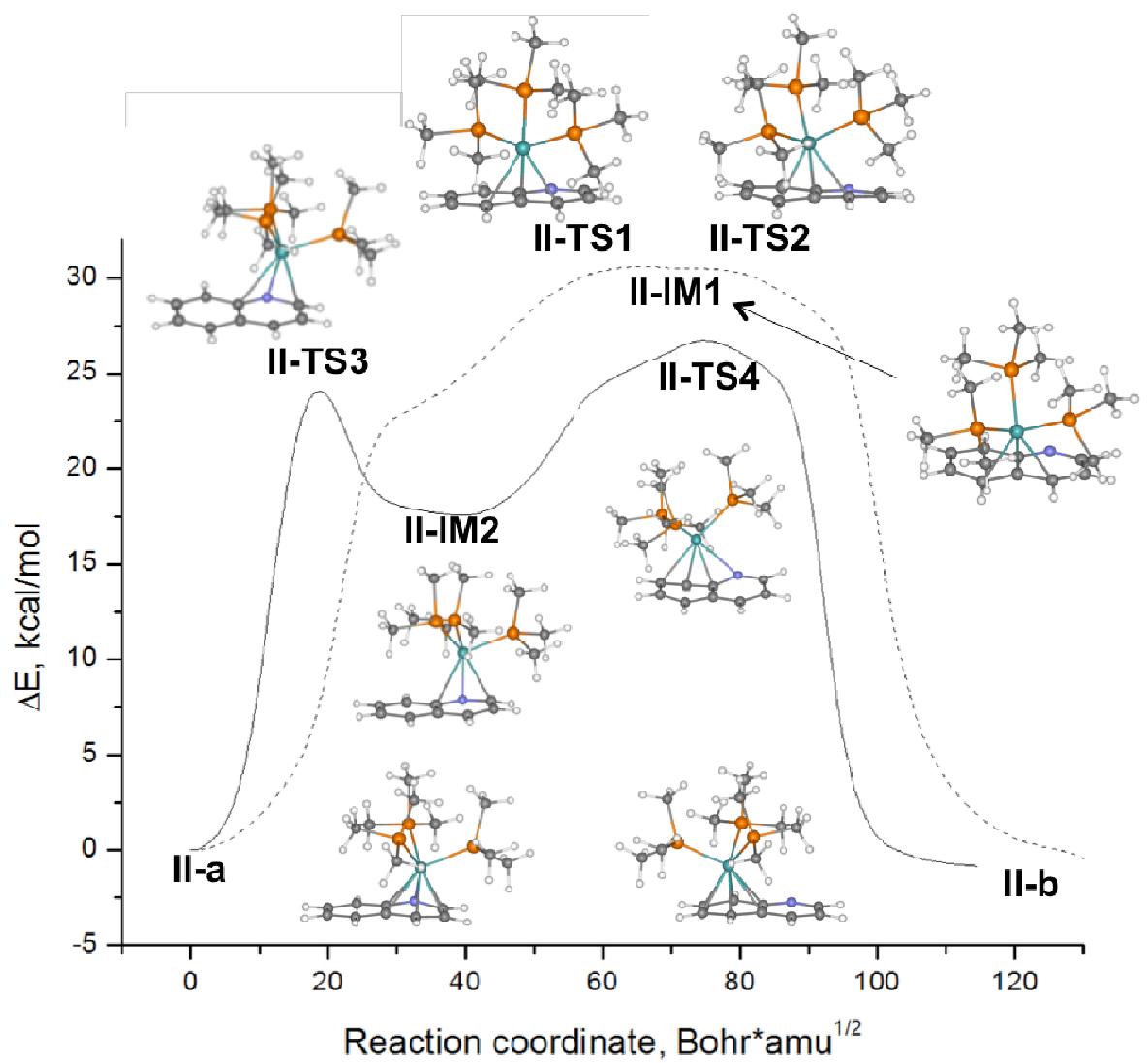

Figure 2. IRC energy profiles for the IRHR II-a $\rightleftarrows$ II-b.

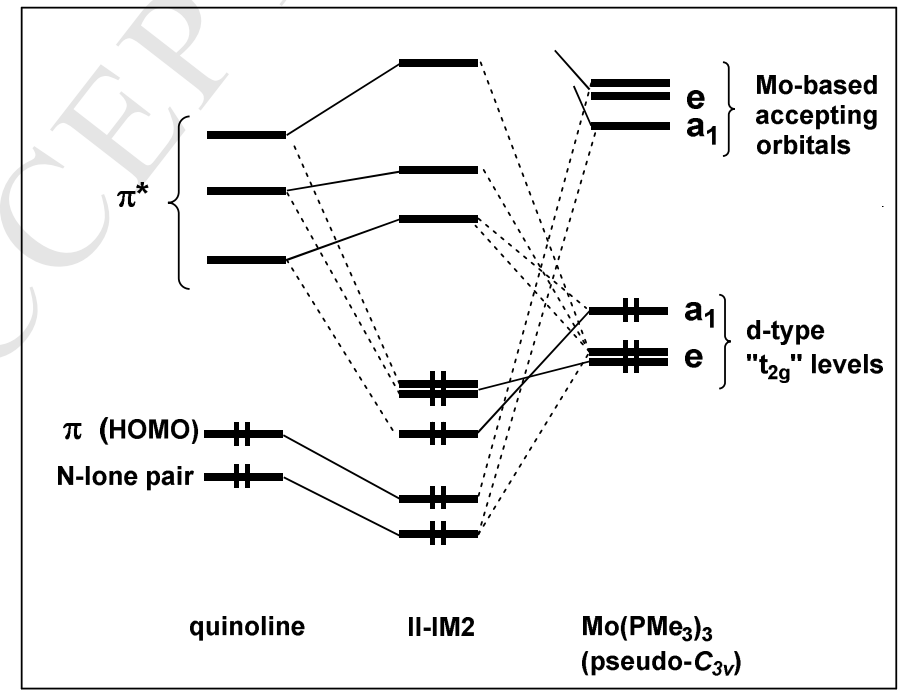

Figure 3. Simplified MO interaction diagram for II-IM2 


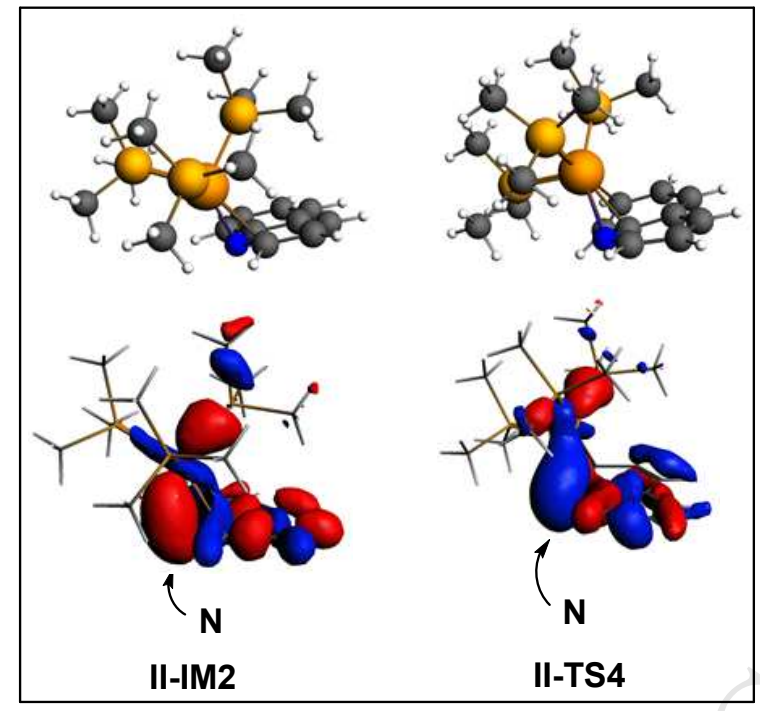

Figure 4. The major occupied MO associated with the Mo-N bonding interaction in II-IM2 (HOMO-8, left) and II-TS4 (HOMO-4, right)
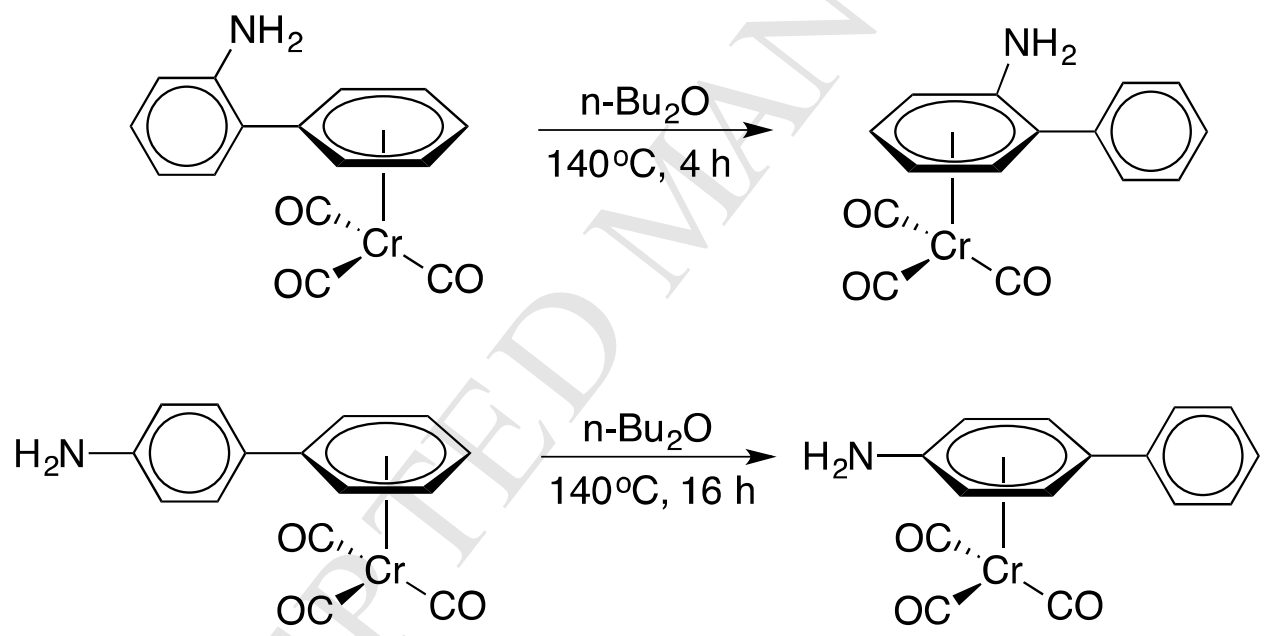

Scheme 4. IRHRs in Cr complexes of ortho- and para-aminobiphenyl (from ref. 35).

Overall, it is quite difficult to select which mechanism is responsible for this rearrangement from available qualitative kinetic and thermodynamic data. It is possible that in the future, precise kinetic data, especially for different substituted complexes, could help making a conclusion about the preferred mechanism. The small difference in the computed activation barriers indicates that probably both mechanisms could occur simultaneously.

Isoquinoline complex. Next, we studied the $\eta^{6} \rightarrow \eta^{6}$-IRHR when the OMG shifts form the heterocyclic to the carbocyclic ring in the Mo complex of isoquinoline III. The higher thermodynamic stability of $\mathbf{I I I}-\mathbf{b}$, in which Mo is localized on the carbocyclic ring $\left(\Delta \Delta G_{150^{\circ} \mathrm{C}}\right.$ 
$=-2.50 \mathrm{kcal} / \mathrm{mol}$ ) is consistent with a practically irreversible III-a $\rightarrow$ III-b IRHR, as observed experimentally.

As opposed to the IRHR for the complexes of quinoline, this IRHR proceeds according to a single mechanism III-a $\rightarrow$ III-TS1 $\rightarrow$ III-IM $\rightarrow$ III-TS2 $\rightarrow$ III-b (Figure 5). In this process, the metal trajectory is direct, crossing approximately the middle of the central C-C edge. All attempts to find alternative mechanisms in which the metal shifts along either the carbocyclic or heterocyclic edge of the ligand were unsuccessful. This process, in which the nitrogen atom is not involved, is characterized by a rather high energy barrier $\left(\Delta G_{150^{\circ} \mathrm{C}}=35.2 \mathrm{kcal} / \mathrm{mol}\right)$. IIITS1, III-IM and III-TS2 are close in geometry and energy. They are characterized by a $\eta^{4}$ coordination mode of isoquinoline, this ligand being strongly folded away from planarity. Whereas the bonding energy between the OMG and the conjugated ligand is larger in III-IM, as compared to II-TS4 (-3.19 eV vs. $-2.39 \mathrm{eV}$, respectively), it is largely balanced by the energy loss associated with the folding of isoquinoline, thus resulting in a considerably higher barrier than in the case of the quinoline complex II.

Quinoxaline complex. Quinoxaline has two nitrogen atoms symmetrically located on one of the aromatic rings (Scheme 3). As in the previous cases, the complex with the metal atom located on the carbocyclic ring is thermodynamically more stable, with an even larger free energy preference $\left(\Delta \Delta G_{130^{\circ} \mathrm{C}}=-7.2 \mathrm{kcal} / \mathrm{mol}\right)$. Both sides of the ligand being symmetrical, a unique $\eta^{6} \rightarrow \eta^{6}$-IRHR pathway was found according to the scheme IV-a $\rightarrow$ IV-TS1 $\rightarrow$ IV-IM $\rightarrow$ IV-TS2 $\rightarrow$ IV-b (Figure 6) with an activation barrier $\Delta G_{130^{\circ} \mathrm{C}}=32.6 \mathrm{kcal} / \mathrm{mol}$ which is also higher than the lowest one found for the IRHR in II, despite of the fact that IV-TS1 and IV-IM are quite structurally similar to II-TS3 and II-IM2. In particular, as for II-IM2, IV-IM exhibits the same $\eta^{2}-\mathrm{C}=\mathrm{N}$ coordination with an additional Mo-C long contact of $2.62 \AA$, with a N lone pair donation to Mo of 0.14e. On the other hand, IV-TS2 looks more like V-IM (or V-TS) rather than II-TS4 (compare Figures 2, 5 and 6). Indeed, it is $\eta^{3}$ rather than $\eta^{4}$ coordinated and the reason for that is that quinoxaline remains close to planarity, contrarily to oxaline in II-TS4. In IV-TS2 the occupied orbitals of quinoxaline donate 0.30e, of which $0.06 \mathrm{e}$ come from the $\mathrm{N}$ lone pair. The backdonation into the quinoxaline $\pi^{*}$ orbitals is $0.69 \mathrm{e}$. All these results suggest that the rigidity of quinoxaline, as compared to quinoline, renders the IRHR more energy demanding, in apparent contradiction with experimental facts. Indeed, according to Parker and coworkers [27], in the case of IV the IRHR from the heterocyclic to the carbocyclic ring proceeds at $130^{\circ} \mathrm{C}$, as compared to $150^{\circ} \mathrm{C}$ for II. However, without 


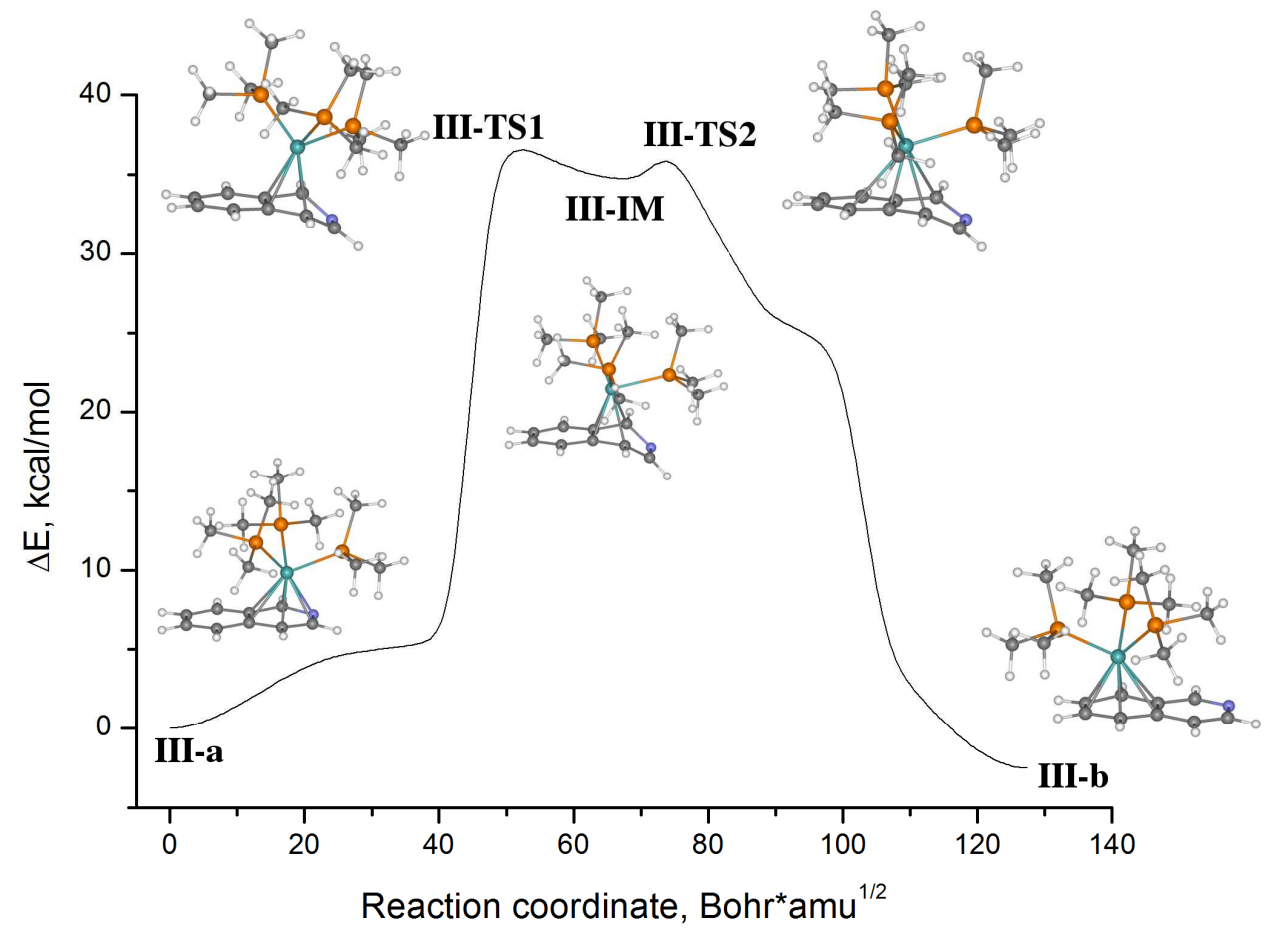

Figure 5. IRC energy profile for the IRHR III-a $\rightleftharpoons$ III-b.

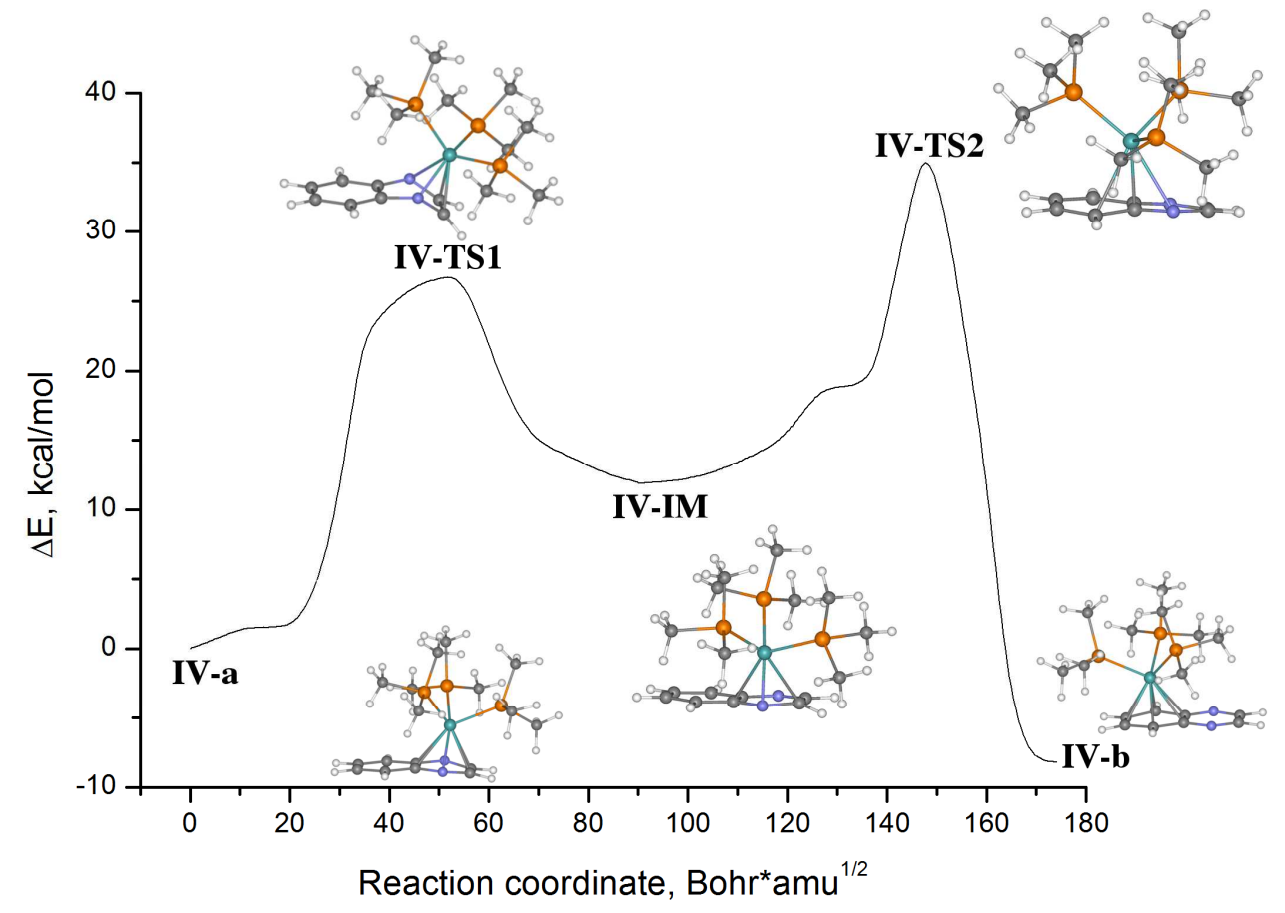

Figure 6. IRC energy profile for the IRHR IV-a $\rightleftharpoons \mathbf{I V}-\mathbf{b}$. 
precise kinetic data for all the complexes in identical conditions it is difficult to discuss this apparent disagreement.

Indolyl complex. The last investigated rearrangement, is the $\eta^{5} \rightarrow \eta^{6}$-IRHR in the indolyl species I. Complex I-a with Mo coordination on the five-membered ring was obtained experimentally from the $\sigma$-complex $\mathrm{MoH}\left[\left(\mathrm{PMe}_{3}\right)_{4}\right]$ (indolyl) I-c after elimination of one trimethylphosphine (Scheme 2) [26]. I-a converts irreversibly at $80^{\circ} \mathrm{C}$ into its thermodynamically more stable $\eta^{6}$-isomer $\mathbf{I}-\mathbf{b}$, which agrees with their computed energy difference $\left(\Delta \Delta G_{80}{ }^{\circ} \mathrm{C}=-1.6 \mathrm{kcal} / \mathrm{mol}\right)$. Two possible mechanisms have been computed for the $\mathbf{I}-\mathbf{a} \rightarrow \mathbf{I}-\mathbf{b}$ process, each of them proceeding in one step along one of the edges of the ligand (Figure 7). Surprisingly, the most favored IRHR pathway is that proceeding along the carbocyclic edge: $\mathbf{I - a} \rightarrow \mathbf{I - T S 1} \rightarrow$ I-b. I-TS1 is $\eta^{2}$-coordinated to the six-member ring (Mo-C $=2.42 \AA$ and $2.33 \AA$ ) with an additional long Mo-C contact to the five-membered ring $(2.87$ $\AA)$. The computed activation barrier $\left(\Delta G_{80^{\circ} \mathrm{C}}=28.4 \mathrm{kcal} / \mathrm{mol}\right)$ is in a very good agreement with the experimental one $\left(\Delta G_{80^{\circ} \mathrm{C}}=27.8 \mathrm{kcal} / \mathrm{mol}\right)$ [26]. The other IRHR pathway, I-a $\rightarrow \mathbf{I}$ TS2 $\rightarrow$ I-b proceeds along the heterocyclic edge, with a slightly higher activation barrier (barrier $\left(\Delta G_{80^{\circ} \mathrm{C}}=30.8 \mathrm{kcal} / \mathrm{mol}\right)$. I-TS2 is somehow the "approximate mirror image" of $\mathbf{I}$ TS1. It is $\eta^{2}$-coordinated to the six-member ring (Mo-C $=2.43 \AA$ and $2.35 \AA$ ) with an additional long Mo-N contact to the five-membered ring (2.81 $\AA$ ). The fragment interaction analysis indicate no significant participation of the nitrogen lone pair in the bonding of I-TS2. Rather, the bonding situations of TS1 and TS2 are rather similar (Figure 7). In TS1 and TS2, the $\pi$ MOs of the indolide anion donate $0.66 \mathrm{e}$ and $0.61 \mathrm{e}$ to the $\left[\mathrm{Mo}\left(\mathrm{PMe}_{3}\right)_{3} \mathrm{H}\right]^{+}$moiety, respectively. The backdonation into the indolide $\pi^{*}$ MOs is $0.65 \mathrm{e}$ and $0.56 \mathrm{e}$, respectively. As a result, the bonding energy between the fragments is slightly larger in I-TS2 than in I-TS2 (5.28 eV vs. $5.18 \mathrm{eV}$ ). Despite the fact that the favored rearrangement pathway does not proceed through the heteroatom side, the activation barrier is lower than for the IRHRs computed for the isoquinoline and quinoxaline species, but still higher than for the quinoline species, in which there is a clear participation of the nitrogen atom in the course of the rearrangement. 


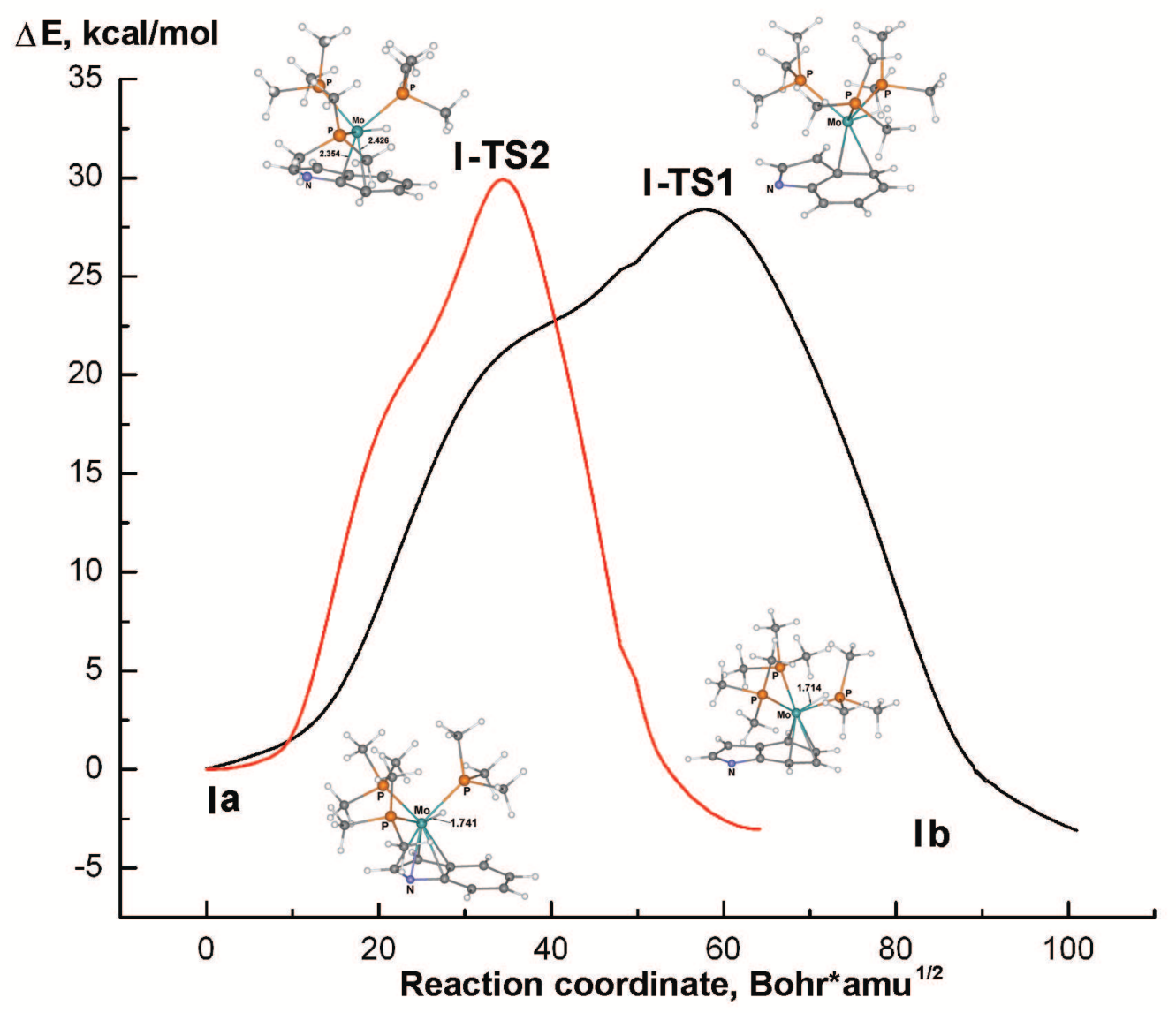

Figure 7. IRC energy profiles for the IRHR I-a $\rightleftharpoons \mathbf{I}-\mathbf{b}$.

\section{SUMMARY AND CONCLUSIONS}

We have investigated by DFT the IRHR mechanisms in a series of MO complexes heteroPALs containing nitrogen and isoelectronic to naphthalene (quinoline, isoquinoline, quinoxaline and indolyl additionally). The computed data are in good correspondence with the available experimental structural and kinetic data [26,27]. With PAL = quinoline, the activation barrier is lowered (as compared to its naphthalene analog) by the participation of the nitrogen lone pair to the bonding in the IRHR process, as well as the larger flexibility of the ligand. This flexibility is due to the less aromatic nature of the hetero-ligand and allows an out-of-plane distortion in the crucial transition state which in turn allows maximizing metalPAL bonding. In the case of isoquinoline, the heteroatom position is unfavorable for intervening efficiently in the transition state and the electronic perturbation it induces is different from the quinoline case. Thus, a different IRHR process with higher activation energy occurs. In the case of quinoxaline the stronger rigidity of the ligand leads also to 
activation energy higher than for quinoline. With one five-membered ring and a four-leg OMG moiety, the system with PAL = indolyl is somewhat different from the other ones. The ligand remains very close to planarity all along the process and no participation of the nitrogen lone pair to the bonding the IRHR pathway is found. Rather, the process going along the carbocyclic edge opposite to nitrogen is slightly preferred. Nevertheless, the activation energy is computed to be only slightly higher than that of the quinoline species and is probably close to that of its indenyl relative. Finally, it should be noted that the possibility of alternative mechanisms involving $\sigma-\mathrm{N}$ intermediate structures was tested and should be ruled out according to our calculations. Theoretical consideration of the inverse photochemical processes (see Schemes 2 and 3) is in progress.

Finally, it is worth to mention that our computed results on these transition complexes of nitrogen-containing PALs, which have been useful in understanding their experimental behavior [26, 27], are important for further progress in the investigation of dynamic activity of heterocycle organometallic complexes. In turn this is important for clarifying the role of heteroatom in the barriers of metal movement along the ligand, with respect to catalytic activity. It is important for material science because carbon atoms in graphene, nanotubes, graphite, fullerenes... could be replaced by heteroatoms in a way that can increase dynamic activity and improve catalytic and material advantages of such compounds.

\section{ACKNOWLEDGMENT}

The authors thank Alexander von Humboldt Stiftung (Bonn, Germany) for providing the workstation and other software accessories to perform DFT calculations. This work was supported by Russian Science Foundation (RSF grant 14-50-00126). ADF calculations were supported by the GENCI grant 2016x087367. 


\section{REFERENCES}

[1] V. P. Ananikov, E. A. Khokhlova, M. P. Egorov, A. M. Sakharov, S. G. Zlotin, A. V. Kucherov, L. M. Kustov, M. L. Gening N. E. Nifantiev, Mendeleev Commun. 25 (2015) 7582.

[2] T. A. Albright, P. Hofmann, R. Hoffmann, C. P. Lillya, P. A. Dobosh, J. Am. Chem. Soc. 105 (1983) 3396-3411.

[3] T. A. Albright, P. I. Dosa, T. N. Grossmann, V. N. Khrustalev, O. A. Oloba, R. Padilla, K. P. C. Vollhardt, Angew. Chem. Int. Ed. Engl.48 (2009) 9853-9857.

[4] (a) Yu. F. Oprunenko, Russ. Chem. Rev. 69 (2000) 683-704. (b) J. O. C. Jiménez-Halla, J. Robles, M. Solà, J. Phys. Chem. A. 112 (2008) 1202-1213.

[5] M. Rosillo, G. Domínguez, J. Pérez-Castells, Chem. Soc. Rev. 69 (2007) 1589-1604.

[6] S. Sarkar, S. Niyogi, E. Bekyarova, R. C. Haddon, Chem. Sci. 2 (2011) 1326-1333.

[7] M. Adams, Y. Li, H. Khot, C. De Kock, P. J. Smith, K. Land, G. S. Smith, G. S. Dalton Trans. 42 (2013) 4677-4685.

[8] C. G. Hartinger, P. J. Dyson, Chem. Soc. Rev. 38 (2009) 391-401.

[9] R. W.-Y. Sun, D.-L. Ma, E. L.-M. Wong, C.-M. Che, C. M. Dalton Trans. 43 (2007) 4884-4892.

[10] D. Natale, J. C. Mareque-Rivas, Chem. Commun. (2008) 425-437.

[11] H. Xiang, J. Yang, J. G. Hou, Q. Zhu, J. Am. Chem. Soc. 128 (2006) 2310-2314.

[12] I. R. Whittall, A. M. McDonagh, M. G. Humphrey, M. Samoc, Adv. Organomet. Chem. 43 (1999) 349-405.

[13] K. H. Dötz, H. C. Jahr, The Chemical Record 4 (2004) 61-71.

[14] E. L. Muetterties, J. R. Bleeke, E. J. Wucherer, T. A. Albright, Chem. Rev. 82 (1982) 499-525.

[15] C. M. Alvarez, R. J. Angelici, A. Sygula, R. Sygula, P. W. Rabideau, Organometallics, 22 (2003) 624-626.

[16] A. K. Kandalam, B. Kiran, P. Jena, X. Li, A. Grubisic, K. H. Bowen, J. Chem. Phys. 126 (2007) 084306.

[17] E. D. Jemmis, M. Manoharan, P. K. Sharma, Organometallics, 19 (2000) 1879-1887.

[18] (a) S. Sarkar, S. Niyogi, E. Bekyarova, R. C. Haddon, Chem. Sci. 2 (2011) 1326-1333.

(b) M. E. Vol'pin, Y. N. Novikov, N. D. Lapkina, V. I. Kasatochkin, Y. T. Struchkov, M. E. Kazakov, A. V. J. Zvarikina, J. Am. Chem. Soc. 97 (1975) 3366-3373. 
[19] S. Sarkar, H. Zhang, J. W. Huang, F. Wang, E. Bekyarova, C. N. Lau, R. C. Haddon, Adv. Mat. 25 (2013) 1131-1136.

[20] Yu. F. Oprunenko, Russ. Chem. Bull. 51 (2002) 907-929.

[21] Yu. F. Oprunenko, I. P. Gloriozov, J. Organomet. Chem. 694 (2009) 1195-1211.

[22] M. V. Zabalov, I. P. Gloriozov, Yu. F. Oprunenko, Yu. D. A. Lemenovskii, Russ. Chem. Bull. 52 (2003) 1567-1572.

[23] Yu. F. Oprunenko, N. G. Akhmedov, D. N. Laikov, S. G. Malyugina, V. I. Mstislavsky, V. A. Roznyatovsky, N. A. Ustynyuk, J. Organomet. Chem. 583 (1999) 136-145.

[24] Yu. F. Oprunenko, I. P. Gloriozov, K. Lyssenko, S. Malyugina, D. Mityuk, V. Mstislavsky, H. Günther, G. von Firks, M. Ebener, J. Organomet. Chem. 656 (2002) 27-42.

[25] K. Shen, X. Tian, J. Zhong, J. Lin, Y. Shen, P. Wu, Organometallics 24 (2005) 127-131.

[26] G. Zhu, J. M. Tanski, D. G. Churchill, K. E. Janak, G. J. Parkin, J. Am. Chem. Soc. 124 (2002) 13658-13659.

[27] G. Zhu, K. Keliang, G. J. Parkin, J. Am. Chem. Soc. 130 (2008) 1564-1565.

[28] D. N. Laikov, Yu. A. Ustynyuk, Russ. Chem. Bull. 54 (2005) 820-826.

[29] J. P. Perdew, K. Burke, M. Ernzerhof, Phys. Rev. Lett. 77 (1996) 3865-3868.

[30] W. J. Stevens, H. Basch, M. Krauss, J. Chem. Phys. 81 (1984) 6026-6033.

[31] R. F. Bader, Atoms in molecules. John Wiley \& Sons, Ltd., Oxford, 1990.

[32] (a) G. te Velde, F. M. Bickelhaupt, S. J. A. van Gisbergen, C. Fonseca Guerra, E. J. Baerends, J. G. Snijders T. Ziegler, J. Comput. Chem. 22 (2001) 931-967. (b) ADF2013, SCM, Theoretical Chemistry, Vrije Universiteit, Amsterdam, The Netherlands, http://www.scm.com.

[33] E. van Lenthe, E. J. Baerends, J. Comput. Chem. 24 (2003) 1142-1156.

[34] For related investigations on isoelectronic naphthalene complexes, see E. O. Fetisov, I. P. Gloriozov, Yu. F. Oprunenko, J.-Y. Saillard, S. Kahlal, Organometallics 32 (2013) 3512-3520 and references therein.

[35] C. J. Czerwinski, I. A. Guzei, K. M. Riggle, J. R. Schroeder, L. C. Spencer, Dalton Trans. 40 (2011) 9439-9446.

[36] C. J. Czerwinski, E. O. Fetisov, I. P. Gloriozov, Yu. F. Oprunenko, Dalton Trans. 42 (2013) 10487-10494.

[37] For a description of the frontier orbitals of an $\mathrm{ML}_{3}$ fragment, see: T. A. Albright, J. K. Burdett, M. H. Whangbo, Orbital Interactions in Chemistry, $2^{\text {nd }}$ Edition, John Wiley \& Sons, Hoboken, New Jersey, 2013. 
The heteroatom highly facilitates IRHR in a quinoline Mo complex.

The $\mathrm{N}$ lone pair participates to the transition state stabilization.

The position(s) of nitrogen atom(s) on the heterocyclic ligand is (are) crucial. 